\title{
Alcohols and other Substance Use/Abuse among Junior Doctors and Medical Students in a Teaching Institute
}

\author{
Shyangwa $P M^{1}$, Joshi $D^{2}$, Lal $R^{3}$ \\ ${ }^{1}$ B.P. Koirala Institute of Health Sciences, Dharan, Nepal. \\ ${ }^{2}$ Mental Hosital, Lagankhel, Lalitur, Nepal. \\ ${ }^{3}$ All Indian Institute of Medical Sciences, New Delhi, India.
}

\begin{abstract}
Substance related disorders have become matters of global concern because of its negative impact on individual health, familial, social and professional life. This study aims to assess prevalence of alcohol and other substance use among students and junior doctors at teaching institute. This descriptive study conducted on medical students, following convenient sampling method. Results revealed the prevalence rates of 'ever used', 'last year used' and 'last month used' were 63.5\%, $56.5 \%$ and $42.5 \%$ respectively. The most preferred substance was alcohol (90.9\%) and only $32.2 \%$ females 'ever used' substance. Cannabis use was seen exclusively among male (15.0\%) students and opioid use was not found. Alcohol is most prevalent substance of use/abuse and was common among house officers and medical students.
\end{abstract}

Key words- Alcohol, Cannabis, Hypnotics, Medical students, Substance use.

\section{INTRODUCTION}

Alcohol and other substances use is a common phenomenon worldwide and Nepal is no exception. Young people are vulnerable to this problem. Typically, substance use starts in adolescent or early adulthood and hits hard subsequently. The consequences of substance use are multifaceted. This habit not only affects health, education and occupational career, but also incurs huge financial and social burden to society. As saying goes, today's young people are tomorrow's future. Any nation heavily depends on the health of youth. Unfortunately, there has been a considerable increase in the use of alcohol and 'hard' drugs particularly among youths. ${ }^{1}$ A vast majority of Nepalese population
$(47 \%)$ is comprised of young people below age of 18 year $^{2}$ an age for college study. Although small in number, medical students represent young population of the society, but career-wise they are extremely responsible.

Professional, particularly medicos with substance use habit might be dangerous for others, as they might lose a sound judgment, fail in responsibility and accrue harm to service receivers. Moreover, professionals like doctors who directly involve with human life, when on such habit, the situation could be disastrous.

Another aspect of substance use habit is - who first use substance at a younger age are more likely to

\section{Correspondence: \\ Dr. Pramod M Shyangwa \\ Department of psychiatry \\ B.P. Koirala Institute of Health Sciences \\ Dharan, Nepal. \\ E-mail: pshyangwa@yahoo.com}


Shyangwa et al. Alcohols and other Substance Use/Abuse among Junior Doctors and Medical Students in a Teaching Institute.

developed dependence or abuse than those who started later. ${ }^{3}$

Literature revealed that physicians, dentists and nurses have far higher rates of dependence on controlled substances such as opioids, stimulants and sedatives than other professionals of compared educational achievement e.g. lawyers. ${ }^{4}$ Although the precise prevalence of problem with alcohol and other substances among medical students and physicians are unknown in this country, a study conducted in general colleges in Kathmandu found that $32.4 \%$ of students had tried different types of drugs. ${ }^{5}$ Though the substance use/abuse problem among local college (Dharan) students is not known, high $(25.8 \%)$ alcohol dependence is found in adult general population of Dharan as assessed by CAGE Questionnaire. ${ }^{6}$ Western literature reports that alcohol and other substance of abuse is common among doctors, which is a disturbing trend. Single and colleagues estimated that about $5.8 \%$ of physician had had alcohol related problem in the past year in Canada. ${ }^{7}$ Although a few studies related to college students' substance use exist in our country, there is hardly any systemic information available regarding substance use/abuse among medical students.

In view of this, and seriousness of the topic, this study was embarked on:

To assess prevalence of alcohol and other substance use among students and junior doctors at BPKIHS.

\section{MATERIALS AND METHODS}

This is a descriptive; cross-sectional study conducted in B.P. Koirala Institute of Health Sciences (BPKIHS), Dharan, a tertiary care center with Undergraduate and Postgraduate teaching programme in all major disciplines.

Inclusion criteria constituted of undergraduates students doing MBBS, Interns, House Officers and Postgraduate students and who do not meet the above criteria were excluded.

Altogether 193 subjects were drawn from 280 students and junior Doctors (Junior Residents) following convenient sampling method.

Questionnaire: This was a pre-coded and structured proforma, used in large studies on rapid assessment of alcohol and other substance use by India Council of Medical Research. ${ }^{8}$ It includes, demographic variables

\begin{tabular}{|c|c|c|}
\hline Occupational status: & Frequency (n) & Percent (\%) \\
\hline Student & 142 & 73.6 \\
\hline Intern & 10 & 5.2 \\
\hline House Officers & 30 & 15.5 \\
\hline Junior Residents & 11 & 5.7 \\
\hline \multicolumn{3}{|l|}{ Age Group: (in Years) } \\
\hline $15-19$ & 25 & 13 \\
\hline $20-24$ & 121 & 62.7 \\
\hline $25-29$ & 38 & 19.7 \\
\hline $30-34$ & 9 & 4.7 \\
\hline \multicolumn{3}{|l|}{ Sex: } \\
\hline Male & 130 & 73.6 \\
\hline Female & 63 & 32.6 \\
\hline \multicolumn{3}{|l|}{ Religion: } \\
\hline Hindu & 182 & 94.3 \\
\hline Buddhist & 8 & 4.1 \\
\hline Sikh & 2 & 1.5 \\
\hline Others & 3 & 1.5 \\
\hline \multicolumn{3}{|l|}{ Nationality: } \\
\hline Nepalese & 160 & 82.9 \\
\hline Indian & 33 & 17.1 \\
\hline Total & 193 & 100 \\
\hline
\end{tabular}

Table 2. Clinical (substance use) Profile of Subjects: "Ever use" of any intoxicant

\begin{tabular}{|c|c|c|}
\hline “Ever Used” & Frequency (n) & Percent (\%) \\
\hline Yes & 122 & 63.2 \\
\hline No & 71 & 36.8 \\
\hline \multicolumn{3}{|c|}{ “Last Year Used" Use of Intoxicant: } \\
\hline Yes & 109 & 56.5 \\
\hline No & 84 & 43.5 \\
\hline \multicolumn{3}{|c|}{ "Last one month" use of intoxicant: } \\
\hline Yes & 82 & 42.5 \\
\hline No & 111 & 57.5 \\
\hline \multicolumn{3}{|c|}{ Break up of 'Last year Used' Intoxicants: } \\
\hline \multicolumn{2}{|c|}{ Type of intoxicant: } & Percent (\%) \\
\hline \multicolumn{2}{|l|}{ Alcohol } & 90.9 \\
\hline \multicolumn{2}{|l|}{ Tobacco } & 68.2 \\
\hline \multicolumn{2}{|l|}{ Cannabis } & 15.0 \\
\hline \multicolumn{2}{|c|}{ Sedative/Hypnotics } & 7.2 \\
\hline \multicolumn{2}{|c|}{ Others: Tadi, Madhu, Tulshi } & 2.0 \\
\hline \multicolumn{2}{|l|}{ Total } & $>100 \% *$ \\
\hline
\end{tabular}

* Note: More than one intoxicant use 


\begin{tabular}{|lcc|}
\hline \multicolumn{3}{|c|}{ Table 3. Sedative/Hypotics use profile in 'last one year' } \\
\hline Sex: & Frequency (N) & Percent (\%) \\
Male & 11 & 8.5 \\
Female & 3 & 4.5 \\
Types of hypnotics: & & \\
Alprazolam (0.25mg) & 12 & 92.0 \\
Diazepam (5mg) & 1 & 8.0 \\
Amount of hypnotics: & & \\
1 Tablet & 11 & 79.0 \\
2-5 Tablet & 3 & 21.0 \\
Cannabis (Ganja) Use\# (15.0\%) & \\
1/4 gram & 8 & 4.1 \\
1-5 gram & 1 & 0.5 \\
Total & 9 & 4.6 \\
\hline \# only males used cannabis & \\
\hline
\end{tabular}

Table 4. Alcohol use among subjects according to Sex and its Type.

\begin{tabular}{lcc} 
Sex: & $\mathbf{N}$ & $\%$ \\
Male & 71 & 54.6 \\
Female & 6 & 9.5 \\
Type of Alcohol: & & \\
Beer & 45 & 58.4 \\
More than one & 29 & 37.6 \\
Whisky & 2 & 2.6 \\
Wine & 1 & 1.2 \\
\hline
\end{tabular}

\section{DISCUSSION}

This study attempts to determine the rate and pattern of substance use/abuse among medical students including junior residents. The use/abuse of different categories, particularly alcohol among doctors has been abundantly reported in literature. Doctors being professionals of responsible and sensitive area of human being, i.e. human health and life; their (doctors) own sound health and accurate judgment remain paramount. Although substance use does not necessarily lead to dependence, nevertheless chaotic life style, may negatively affect delivery of health service.

In our study, majority of subjects were drawn from MBBS stream (the biggest number in the institute) and lowest being interns and junior residents (J/Rs). On enquiry about longitudinal substance use- $63.2 \%, 56.5 \%$ and $42.5 \%$ reported 'ever used', 'last year used' and 'last month used' respectively. Although these timeframe use ('ever'; 'last year'; 'last month' use) findings were not analyzed in detail to pigeonhole to psychiatric definitions of dependence/abuse, the high rate of substance use in all these headings was high, including 'last month use' suggests possible significant problem, (substance abuse) among subjects.

The most favored substance of use in the last year was alcohol $(91 \%)$ followed by tobacco $(68.2 \%)$ and cannabis $(15.0 \%)$, which might reflects the substance use pattern of Nepalese society. These findings are well consistent with findings reported by a survey conducted on college students in Kathmandu valley ${ }^{9}$ where $18.0 \%$ of the school and $25.0 \%$ of the college students had casual use of alcohol and $3.5 \%$ of school and $10.0 \%$ of college students respectively had used alcohol quite frequently.

Another study conducted on school and campus students (sample size: 6218), 'current alcohol users' were recorded to be at $12.7 \%$ ranking first followed by cannabis and heroin. ${ }^{10}$ In Nepalese context, alcohol use is common in 'Matawali' 1 category of people (based on social sanction of intoxicants use), in which use of intoxicants, mainly alcohol is not only culturally sanctioned, but rather encouraged. Another category- 'Tagadhari' however, is socially barred from alcohol use, also are gradually taking a liberal attitude about alcohol use and its use is catching up. Social barrier of 'user' and 'non-user' is collapsing

\begin{tabular}{|c|c|c|c|c|c|}
\hline Occupational Status & $\mathbf{N}$ & $\%$ & Amount in a single setting & $\mathbf{N}$ & $\%$ \\
\hline \multirow[t]{5}{*}{ Student } & $45 / 142$ & 31.7 & & & \\
\hline & & & $30-60 \mathrm{ml}$ & 35 & 77.7 \\
\hline & & & $1 / 4^{\text {th }}$ bottle & 7 & 15.5 \\
\hline & & & $120 \mathrm{ml}$ & 2 & 4.4 \\
\hline & & & 1 bottle & 1 & 2.2 \\
\hline \multirow[t]{3}{*}{ Interns } & $4 / 10$ & 40.0 & & & \\
\hline & & & $30-60 \mathrm{ml}$ & 3 & 60.0 \\
\hline & & & $1 / 4^{\text {th }}$ bottle & 1 & 40.0 \\
\hline \multirow[t]{3}{*}{ House Officer } & $20 / 30$ & 66.6 & & & \\
\hline & & & $30-60 \mathrm{ml}$ & 12 & 75.0 \\
\hline & & & $1 / 4^{\text {th }}$ bottle & 8 & 25.0 \\
\hline \multirow[t]{4}{*}{ Junior Resident } & $8 / 11$ & 72.0 & & & \\
\hline & & & $30-60 \mathrm{ml}$ & 5 & 62.5 \\
\hline & & & $1 / 4^{\text {th }}$ bottle & 2 & 25.0 \\
\hline & & & $120 \mathrm{ml}$ & 1 & 12.5 \\
\hline Total & 77 & 100 & & & \\
\hline
\end{tabular}


rapidly, which is reflected in this study as majority of respondents belonged to Hindu religion, alcohol use was quite high though.

But an Iranian study reported that tobacco was the most prevalent form of substance use ${ }^{11}$, which can be understood as alcohol use is banned by Muslim law.

This study reveals that $\mathrm{J} / \mathrm{Rs}$ were the highest user $(72.0 \%)$ of alcohol and lowest being MBBS students $(31.7 \%)$, indicating the trend that alcohol use increases with progress in educational ladder; perhaps with age too. Among alcoholic beverages, most liked one was beer $(58.4 \%)$. Female students still are lesser alcohol user $(\sim 10.0 \%)$ compared to males ( $25.0 \%)$. When analyzed the amount of alcohol use, the majority had drunk moderate amount (30-60 ml) hard drink in a single sitting.

About $68 \%$ respondents reported to be using tobacco, reflecting the high magnitude of the problem. One among many implications of tobacco use would be its facilitating property for other stronger (hard) substance/s use, which is commonly known as "gate way" drug. ${ }^{12}$ Another 'gate way' substances include less socially disapproved ones, less strong alcohol like wine (in our context, home brewed beer, Jand, Tongba, Chhyang etc.) and cannabis. In the wake of wide drive of banning tobacco use in public and official places, including Nepal, and also doctor being a role model, tobacco use by medical professional would be demeaning.

Though relatively smaller in proportion (15.0\%), cannabis use was also found to be remarkable one. Only male subjects used it. Recent study conducted at the same setting showed that $13.5 \%$ medical students used cannabis in the last three months. ${ }^{13}$ The least number of respondents used hypnotics/sedatives (7.2\%), however contrary to cannabis; females were also into it $(4.5 \%)$. One significant implication of use of these drugs would be potential abuse in the future owing to their easy access to medical professionals.

Limitation of the study constitutes the small sample size, particularly of house officer and Junior Residents and also not having analyzed the findings in order to categorize subjects' substance use status according to standard classificatory system.

\section{CONCLUSION}

Alcohol is most prevalent substance of use/abuse and is common among house officers and medical students. Cannabis use was seen exclusively among male students. Fortunately, hard drugs like opioid use was almost absent. Nevertheless, current level of other substance use/abuse warrants timely identification and intervention. Preventive measures like awareness programs, dissuading messages, and recreation activities need to be promoted.

\section{REFERENCES}

1. Mohan D. Rapid assessment survey instruction manual. Department of psychiatry, All India Institute of Medical Sciences (AIIMS), New Delhi 1999.

2. Shrestha DM, Shrestha BK. Paper presented in WHO regional consultation on tobacco and alcohol. Colombo, Srilanka, November 1997.

3. Population Reference Bureau, Washington D.C. 2000 Kids account international data sheet.

4. Marjorie JH. Diagnosis and treatment of teen drug use. Medical Clinics of North America 2000; 84: 927-966.

5. Jaffe JH. Introduction and overview substance-related disorders. In: Sadock BJ and Sadock VA (eds). Comprehensive textbook of psychiatry: Lippincott Williams and Witkins 2005: 924.

6. Subba C. Alcohol and drug abuse among indigenous population. Proceeding of DAPAN; 1995 Jul 22-23; Kathmandu.

7. Jhingan HP, Shyangwa PM, Sharma A, Prasad KMR, Khandelwal SK. Prevelance of alcohol dependence in a town in Nepal as assessed by the CAGE Questionnaire.

Addiction 2003; 98: 339-349.

8. Single E, Truong MV, Adlaf E, Ialomiteanu A. Canadian Profile-1999. Toronto: Centre for Addiction and Mental Health 1999.

9. Roche P, Kohler U, Pandey GR. Drug use among Nepali youth: A survey of Kathmandu Schools and College Students; United Mission to Nepal 1988.

10. Bhandari B, Subba C. Students and drug in Nepal: drug abuse prevention association Nepal 1992.

11. Ahmadi J, Ghanizadeh A. Current Substance use among Iranian medical students. Indian journal of Psychiatry 2004; 43 (2): 157-161.

12. Winick C, Norman RL. Epidemiology. In: Lowinson J H, Ruiz P, Milliman RB Langrod JH, eds. Substance abuse: A comprehensive textbook $4^{\text {th }}$ ed: Lippincott, Williams and Wilkins 2005; 4:19.

13. Shyangwa PM, Shakya Dr, Koirala R. Anxiety in medical students using cannabis. Souvenir (abstract), National CME of Psychiatrists' Association Nepal (PAN), 29-30, Nov, Dharan 2007: 2 . 